\title{
Folate status in women of childbearing age in the Urban Metropolitan Region of Chile: results from the National Health Survey 2016-2017
}

\author{
Dolores Busso ${ }^{1,2, *}$ (1), Guadalupe Echeverría ${ }^{3}$, Alvaro Passi-Solar ${ }^{4,5}$, Fernanda Morales ${ }^{4}$, \\ Marcelo Farías ${ }^{6}$ and Paula Margozzini ${ }^{4, *}$ \\ 'Universidad de los Andes, Chile, School of Medicine, Biomedical Research and Innovation Center, Monseñor Álvarez \\ del Portillo 12455, 7620001 Las Condes, Santiago, Chile: ${ }^{2}$ Pontificia Universidad Católica de Chile, School of \\ Medicine, Department of Nutrition, Diabetes and Metabolism, Santiago, Chile: ${ }^{3}$ Pontificia Universidad Católica de \\ Chile, School of Medicine, Center of Molecular Nutrition and Chronic Diseases, Santiago, Chile: ${ }^{4}$ Pontificia \\ Universidad Católica de Chile, School of Medicine, Department of Public Health, Diagonal Paraguay 362, 8330077 \\ Santiago, Chile: ${ }^{5}$ University College London, Department of Epidemiology and Public Health, London, UK: ${ }^{6}$ Pontificia \\ Universidad Católica de Chile, School of Medicine, Division of Obstetrics and Gynecaology, Santiago, Chile
}

Submitted 12 February 2019: Final revision received 25 June 2020: Accepted 2 July 2020: First published online 10 September 2020

\begin{abstract}
Objective: To analyse serum folate levels in women of childbearing age in the Metropolitan Region (MR) of Chile.

Design: Cross-sectional design as part of the 2016-2017 National Health Survey (Encuesta Nacional de Salud, ENS 2016-2017), using a household-based multistage stratified random sample. Serum folate levels measured by electrochemiluminescence immunoassay in fasting venous blood samples were classified as deficient $(<4.4 \mathrm{ng} / \mathrm{ml})$, normal $(4 \cdot 4-20 \mathrm{ng} / \mathrm{ml})$ or supraphysiological $(>20 \mathrm{ng} / \mathrm{ml})$. Setting: The MR of Chile.

Participants: Women of reproductive age (15-49 years, $n$ 222) from the MR participated in the ENS 2016-2017.

Results: The mean, median and range of serum folate were 14.2 (sE 0.4), 13.9 and $2 \cdot 1-32 \cdot 2 \mathrm{ng} / \mathrm{ml}$, respectively. Folate deficiency was detected in $0.9 \%$ of women, while $7.0 \%$ had supraphysiological levels of the vitamin. No significant effects of age, educational level, marital status, parity, smoking status or nutritional status on serum folate levels were detected by univariate or multivariate analyses. Intake of folic acid supplements showed a significant association with serum folate levels, but only $1.2 \%$ of women used supplements.

Conclusions: Folate deficiency in women of reproductive age living in the MR of Chile is almost inexistent according to the ENS 2016-2017, suggesting that the current population-wide mandatory folic acid fortification of flour is an effective and equitable measure to prevent folate deficiency. These results support the option of maintaining current folic acid fortification in Chile, particularly based on the low adherence to supplementation regimes evidenced in other populations.
\end{abstract}

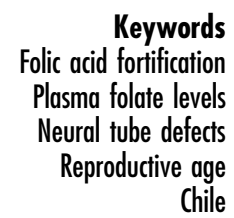

In 1991, the UK Medical Research Council demonstrated that periconceptional supplementation with folic acid could significantly reduce the incidence of neural tube defects $(\mathrm{NTD})^{(1)}$. NTD are a group of congenital malformations resulting from incomplete closure of the neural tube, the embryonic precursor of the brain and spinal $\operatorname{cord}^{(2)}$. Because human neural tube closure takes place 3 weeks after conception, before most women are even aware of their pregnancy ${ }^{(3)}$, adequate folate levels should be provided to all fertile women to be effective at preventing NTD. This situation is particularly relevant in regions such as Latin America, where $69 \%$ of pregnancies are unintended ${ }^{(4)}$.

Since the early 1990s, different strategies to increase blood folate concentration in women of reproductive age have been considered. Interventions designed to increase the intake of folate-rich foods were rapidly discarded, as they were ineffective in improving folate status ${ }^{(5)}$. In most populations, folic acid supplement use is also ineffective because of low awareness of patients and healthcare providers to the use of folic acid before pregnancy ${ }^{(6,7)}$, together 
with low adherence to the use of pills and with the existence of socio-economic disparities (high costs and low availability) of vitamins in specific locations ${ }^{(8,9)}$. Folic acid mandatory fortification of food is considered an effective measure to provide sufficient folate to women before they get pregnant. Enrichment of cereal grain products with folic acid was first implemented in the USA in $1998^{(3)}$. Since then, folic acid fortification of wheat, maize and/or rice flour has been adopted as a cost-effective public health policy in more than eighty countries ${ }^{(10,11)}$, and its implementation has proven to reduce the incidence of NTD significantly ${ }^{(12,13)}$.

In Chile, mandatory fortification of wheat flour with $2.2 \mathrm{mg}$ folic acid/ $\mathrm{kg}$ was first implemented in 2000. This policy was designed to increase the average intake of folic acid by $400 \mu \mathrm{g} / \mathrm{d}$ in women of reproductive age. In 2003, Hertrampf et al. ${ }^{(14)}$ showed that serum folate levels had risen from 4.3 to $16.4 \mathrm{ng} / \mathrm{ml}$ in a cohort of 605 young women from low socio-economic households. The policy showed to be effective in decreasing the incidence of NTD by $43 \%$ from pre-fortification (1999-2000) to postfortification (2001-2002) ${ }^{(15)}$. The cost-effectiveness of this intervention was later demonstrated by Llanos et al. ${ }^{(16)}$, who showed that the overall cost of surgery and long-term rehabilitation for patients with NTD 'significantly exceeded the investment incurred by the milling industry'.

Evidence worldwide and from Chile suggested that specific population subgroups or individuals might suffer adverse effects if exposed to high levels of folic acid ${ }^{(17-21)}$. Positive associations between high serum folate with anaemia and enhanced cognitive decline in the elderly with vitamin $\mathrm{B}_{12}$ deficiency, as well as increased risk or progression of some types of cancer, were shown both internationally and in Chile ${ }^{(20-24)}$. High folic acid intake was also shown to interfere with the action of certain drugs, for example, those used to treat epilepsy, some autoimmune diseases and malaria ${ }^{(17)}$. Those potential harmful effects of high folic acid intake, together with international concerns about the increased supply of foods fortified with folic acid, led the Chilean government to adjust the fortification policy in 2009 to $1.8 \mathrm{mg} / \mathrm{kg}$ wheat flour (range $1 \cdot 0-2 \cdot 6 \mathrm{mg} / \mathrm{kg}$ ).

In this work, we analysed the current folate status of a subgroup of Chilean women of childbearing age for the first time after the implementation of the policy adjustment. The current study, aimed at providing evidence to assess the need for adjustment of the public policy of flour fortification with folic acid, was part of the 2016-2017 National Health Survey (Encuesta Nacional de Salud, ENS 2016-2017).

\section{Methods}

\section{Participants and data collection}

All women of childbearing age participating in the ENS 2016-2017 and living in the Metropolitan Region (MR) were selected for folate determinations, because of budget and logistic constraints (further information in the last paragraph of this section). The MR is one of the sixteen administrative and political regions from Chile. Although it is one of the smallest regions, it is the most densely populated and contains the capital city (Santiago) and its urban suburbs.

The ENS 2016-2017 is a national cross-sectional study that used stratified, multistage and clustered random sampling of households. The strata included fifteen administrative regions and urban/rural areas, from where counties were selected according to the proportion of people aged 15 years or more. Households and one person per home were selected at random in each county. The ENS was designed to estimate, at the national and regional levels, the prevalence of common chronic conditions (e.g., expected 6 and $30 \%$ of diabetes and hypertension, respectively) and associated risk factors by sex and age groups. The Kish method was used to select one participant per household randomly ${ }^{(25)}$. The number of selected households was 9303: 23.2 \% were not present at home (not reached) or were non-eligible (i.e., pregnant women or persons showing aggressive behaviour, with potential risk for the interviewer) and $9.8 \%$ refused to participate. The household national survey response rate (participants interviewed/participants sampled) was $67 \%{ }^{(26)}$. No replacements were performed. The participants included in the ENS 2016-2017 survey were 6233 noninstitutionalised men and women aged 15 years or more (Fig. 1). In the MR, the response rate at the first visit was $62 \%$ (31 and $7 \%$ non-contact and refusal, respectively). The levels of response both nationwide and in the MR are comparable to those achieved by other national health examination surveys ${ }^{(26)}$.

Data were collected in two visits, lasting nearly $1 \mathrm{~h}$ each. During the first home visit, a lay interviewer applied health questionnaires using electronic data capture devices. Eighty-nine percentage of the interviewed participants received a second visit by a trained nurse, who applied questionnaires, measured blood pressure, conducted anthropometric measurements and collected fasting blood and urine samples. The nurse also recorded the medications participants were currently using (prescribed or not) via a detailed inventory. Medications were classified using the anatomical therapeutic chemical (ATC) classification system, in which supplements of folate and derivatives are given the code ATC B03BB (i.e., Ref. (27)). Similar response rates to the nurse visit were registered in the MR and the rest of the country.

Weight assessment was done with the HN289 OMRON digital scale (OMRON Healthcare Co. Ltd, accuracy 5-150 kg: $\pm(1 \%+0 \cdot 1 \mathrm{~kg}))$. Height was measured with a set square and a chrome-plated tape measure against a wall, as reported previously ${ }^{(28,29)}$. The maximum period of stability of folate samples protected from light, if refrigerated, is $2 \mathrm{~d}^{(30)}$. Among 241 women in childbearing age in the MR, 225 blood samples were processed to obtain serum within $1 \mathrm{~h}$ of their collection and transported in $<2 \mathrm{~d}$ at $4^{\circ} \mathrm{C}$ to the Clinical 


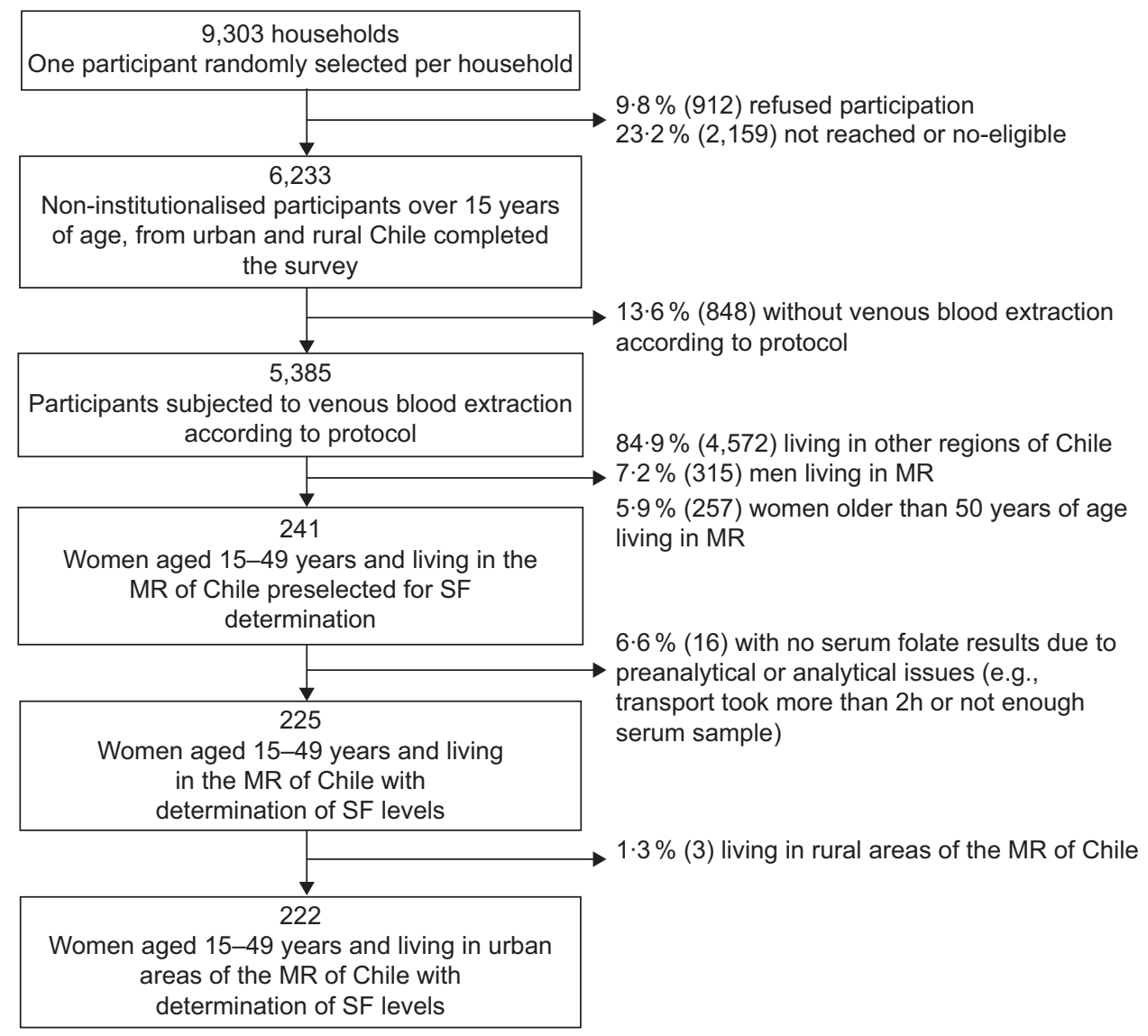

Fig. 1 Flow diagram of the subsample selected from Encuesta Nacional de Salud 2016-2017 for serum folate (SF) determinations: women of childbearing age living in the urban Metropolitan Region (MR) of Chile

Laboratory Red Salud UC CHRISTUS from Pontificia Universidad Católica de Chile in Santiago. Women subjected to serum folate analyses from the MR were mainly from urban areas ( $n$ 222), and only three women lived in rural areas, so the latter were excluded from the analyses.

\section{Determination of serum folate concentrations}

Serum folate concentrations were measured by electrochemiluminescence immunoassay, using the Roche Diagnostics 'Cobas 8000-E602 Immunoassay Analyzer'. The assay coefficients of variation were 10.6 and $7.3 \%$ at mean iodine concentrations of 2.5 and $6.7 \mathrm{ng} / \mathrm{ml}$, respectively.

The serum folate levels were classified into deficient $(<4.4 \mathrm{ng} / \mathrm{ml})$, normal $(4.41-20 \mathrm{ng} / \mathrm{ml})$ or supraphysiological ( $>20 \mathrm{ng} / \mathrm{ml}$ ) according to the WHO's guidelines ${ }^{(31)}$. The supraphysiological category was subdivided into two sub-categories: high $(>20-26 \mathrm{ng} / \mathrm{ml})$ and very high $(>26 \mathrm{ng} / \mathrm{ml})$, according to the reported cut-offs at which free folic acid is detected and cognitive deficits are reported, respectively ${ }^{(22,32)}$.

\section{Socio-demographic, lifestyle and nutritional status population variables}

The following variables were considered in the analysis: age, educational level (low, $<8$ years $v$. medium, $8-12$ years $v$. high, 13 or more years of schooling), marital status (married or cohabiting $v$. single or divorced or widowed), parity (number of births), smoking status (smoker $v$. nonsmoker) and nutritional status (defined as underweight $\left(\mathrm{BMI}<18.5 \mathrm{~kg} / \mathrm{m}^{2}\right.$ ), normal (BMI 18.5 to $<25 \mathrm{~kg} / \mathrm{m}^{2}$ ), overweight (BMI 25 to $<30 \mathrm{~kg} / \mathrm{m}^{2}$ ) and obese (BMI $\geq$ $\left.\left.30 \mathrm{~kg} / \mathrm{m}^{2}\right)\right)^{(33,34)}$. BMI $\left(\mathrm{kg} / \mathrm{m}^{2}\right)$ was derived from height and weight.

\section{Statistical methods}

Prevalence rates, means and medians were calculated with multistage sampling and adjusted following a poststratification procedure using Chile's 2017 census estimates. SE and $95 \%$ CI were calculated using the Taylor series expansion method ${ }^{(35)}$.

Analyses were based on complete cases. $P$-values $<0.05$ were classed as statistically significant (two-tailed). Associations between serum folate levels and all variables included in the study (socio-demographic, lifestyle and nutritional status) were established by univariate and multivariate linear regression analyses, using SPSS software (version 17.0). The multivariate linear regression model for serum folate levels was adjusted for age (years) and nutritional status (BMI $\left(\mathrm{kg} / \mathrm{m}^{2}\right)$ (continuous); educational level, marital status and parity (categorical); physical 
Table 1 Socio-demographic characteristics of women aged 15-49 years living in urban areas of the Metropolitan Region of Chile, Encuesta Nacional de Salud 2016-2017

\begin{tabular}{|c|c|c|}
\hline & $\begin{array}{c}\text { No. of } \\
\text { participants }\end{array}$ & $\begin{array}{c}\text { Expanded } \\
\text { frequency }(\%)\end{array}$ \\
\hline \multicolumn{3}{|l|}{ Age range (years) } \\
\hline $15-19$ & 27 & $13 \cdot 9$ \\
\hline $20-29$ & 74 & 33.8 \\
\hline 30-39 & 71 & 28.9 \\
\hline $40-49$ & 50 & $23 \cdot 3$ \\
\hline \multicolumn{3}{|l|}{ Educational level } \\
\hline Low (<8 years of schooling) & 12 & 4.7 \\
\hline Medium (8-12 years of schooling) & 113 & $57 \cdot 0$ \\
\hline High (>12 years of schooling) & 97 & 38.4 \\
\hline \multicolumn{3}{|l|}{ Marital status } \\
\hline Married & 93 & 35.4 \\
\hline Separated, divorced or widowed & 20 & $10 \cdot 4$ \\
\hline Single & 109 & $54 \cdot 2$ \\
\hline \multicolumn{3}{|l|}{ Parity (no. of pregnancies) ${ }^{*}$} \\
\hline 0 & 71 & 34.0 \\
\hline Between 1 and 2 & 78 & 34.2 \\
\hline 3 or more & 69 & $31 \cdot 8$ \\
\hline \multicolumn{3}{|l|}{ Smoking status } \\
\hline Non-smoker & 144 & $67 \cdot 7$ \\
\hline Smoker & 78 & $32 \cdot 3$ \\
\hline \multicolumn{3}{|l|}{ Physical activity (during leisure time) } \\
\hline No & 196 & 88.0 \\
\hline Yes & 26 & $12 \cdot 0$ \\
\hline \multicolumn{3}{|l|}{ Nutritional status } \\
\hline Underweight & 2 & $1 \cdot 7$ \\
\hline Normal & 68 & 29.7 \\
\hline Overweight & 86 & $40 \cdot 9$ \\
\hline Obese & 66 & $27 \cdot 7$ \\
\hline \multicolumn{3}{|l|}{ Folic acid supplementation } \\
\hline No & 218 & $98.8 \%$ \\
\hline Yes & 4 & $1.2 \%$ \\
\hline
\end{tabular}

${ }^{*}$ Data from parity of four women were not reported.

activity during leisure, current smoking status and folic acid supplementation (dichotomic). Median and percentiles were calculated using SAS 9.4 (2013) statistical software. All analyses were adjusted for the complex survey design of the ENS.

\section{Results}

\section{Socio-demographic characteristics}

The socio-demographic characteristics of the weighted sample are shown in Table 1 . The current study involved 222 women between the ages of 15 and 49 years (mean age $31.2 \pm 0.9$ years old). Almost $91 \%$ of women had medium or high educational levels (more than 8 years of schooling). Regarding their reproductive history, around one-third of the sample was nulliparous, one-third had given birth once or twice and the remainder had given birth more than three times. Thirty-two percentage of the women declared they were smokers. Eighty-eight percentage were classified as sedentary, and almost $70 \%$ of the participants were either overweight or obese (mean BMI $27.9 \pm 0.5 \mathrm{~kg} / \mathrm{m}^{2}$ ). Only $1.2 \%$ of the participants were taking folic acid supplements.
Table 2 Serum folate levels in women of childbearing age living in urban areas of the Metropolitan Region of Chile, Encuesta Nacional de Salud 2016-2017

\begin{tabular}{lcc}
\hline $\begin{array}{l}\text { Folate status (folate } \\
\text { range in } \mathrm{ng} / \mathrm{ml})\end{array}$ & $\begin{array}{c}\text { Unweighted sample size } \\
\text { (no. of participants) }\end{array}$ & $\begin{array}{c}\text { Expanded } \\
\text { frequency }(\%)\end{array}$ \\
\hline Deficient $(<4.4)$ & 2 & 0.9 \\
Normal $(4.4-20)$ & 207 & $92 \cdot 1$ \\
High $(>20-26)$ & 6 & 3.7 \\
Very high $(>26)$ & 10 & 3.3 \\
\hline
\end{tabular}

\section{Plasma folate levels}

Results indicating the prevalence of folate deficiency and excess are shown in Table 2 . Only $0.9 \%$ of the women presented serum folate deficiency with levels below $4.4 \mathrm{ng} / \mathrm{ml}$. Most participants $(92.1 \%$ ) showed serum folate levels that were in the physiological range $(4 \cdot 4-20 \mathrm{ng} / \mathrm{ml})$. On the other hand, $7 \cdot 0 \%$ of women exhibited supraphysiological serum folate concentrations. In this group, $3.7 \%$ exhibited high folate levels $(>20 \mathrm{ng} / \mathrm{ml})$, and $3.3 \%$ were in the very high or highest folate $(>26 \mathrm{ng} / \mathrm{ml})$ category.

The mean serum folate level of women of childbearing age living in the urban MR was $14.2 \pm 0.4 \mathrm{ng} / \mathrm{ml}$, and the median was $13.5 \mathrm{ng} / \mathrm{ml}$ (range $2 \cdot 1-32 \cdot 2 \mathrm{ng} / \mathrm{ml}$ ). Table 3 shows the percentile distribution in those women. Mean and median serum folate concentrations were similar across all socio-demographic variables measured (Table 4). A significant difference in serum folate levels was only found by folic acid supplementation $(P=0.028)$, where women with supplementation had, on average, $70 \%$ higher levels of serum folate than women without folic acid supplementation $(24.0 \pm 5 \cdot 2 v \cdot 14 \cdot 01 \pm 0.4 \mathrm{ng} / \mathrm{ml}$, respectively).

Linear regression was performed to examine the relationship between serum folate concentrations with age, educational level, marital status, parity, smoking status, nutritional status and folic acid supplement use (Table 5). The only variable that showed a significant association with folate levels after adjusting for other variables was folic acid supplement use. Women who did not use folic acid supplements presented $9.9 \mathrm{ng} / \mathrm{ml}$ lower mean serum folate levels than those taking supplements. However, only $1.2 \%$ of women in our study used supplements.

\section{Discussion}

In 2000, the implementation of mandatory folic acid fortification of wheat flour in Chile increased circulating folate levels in women of childbearing age ${ }^{(14)}$ and concomitantly reduced the incidence of NTD by $43 \%{ }^{(15)}$. The folate status of women of reproductive age in Chile was last analysed a few years after, in 2003, in women of low socio-economic households $^{(14)}$.

The aim of this paper was to determine the current folate status in Chilean women of reproductive age belonging to different socio-demographic groups for the first time after the last adjustment to the folic acid fortification policy in 
Table 3 Percentile distribution of serum folate in women of childbearing age living in urban areas of the Metropolitan Region of Chile

\begin{tabular}{lccccccccccc}
\hline Percentile & $5 \%$ & $10 \%$ & $20 \%$ & $30 \%$ & $40 \%$ & $50 \%$ & $60 \%$ & $70 \%$ & $80 \%$ & $90 \%$ & $95 \%$ \\
Serum folate $(\mathrm{ng} / \mathrm{ml})$ & 7.6 & 9.4 & 10.9 & 12.2 & 12.8 & 13.5 & 14.6 & 15.4 & 16.7 & 18.9 & 24.1 \\
SE & 1.7 & 0.9 & 0.4 & 0.4 & 0.3 & 0.4 & 0.4 & 0.3 & 0.6 & 1.8 & 2.2 \\
\hline
\end{tabular}

Table 4 Serum folate levels by socio-demographic characteristics in women of childbearing age living in urban areas of the Metropolitan Region of Chile

\begin{tabular}{|c|c|c|c|c|c|c|}
\hline & No. of participants & Mean (ng/ml) & $\mathrm{SE}(\mathrm{ng} / \mathrm{ml})$ & Median (ng/ml) & Range (ng/ml) & $P$ \\
\hline \multicolumn{7}{|l|}{ Age range (years) } \\
\hline $15-19$ & 27 & $13 \cdot 6$ & 1.0 & $13 \cdot 0$ & $2 \cdot 1-27 \cdot 4$ & \multirow[t]{4}{*}{0.57} \\
\hline $20-29$ & 74 & $14 \cdot 3$ & 0.9 & $13 \cdot 8$ & $4 \cdot 7-32 \cdot 2$ & \\
\hline $30-39$ & 71 & $13 \cdot 8$ & 0.4 & $13 \cdot 1$ & $8 \cdot 2-31 \cdot 1$ & \\
\hline $40-49$ & 50 & $15 \cdot 0$ & 0.8 & $14 \cdot 3$ & $2 \cdot 1-27 \cdot 9$ & \\
\hline \multicolumn{7}{|l|}{ Educational level } \\
\hline Low ( $\leq 8$ years of schooling) & 12 & 14.5 & 1.9 & $11 \cdot 3$ & $2 \cdot 1-27 \cdot 1$ & \multirow[t]{3}{*}{0.76} \\
\hline Medium ( $8-12$ years of schooling) & 113 & 13.9 & 0.5 & 13.4 & $2 \cdot 1-31 \cdot 1$ & \\
\hline High ( $\geq 12$ years of schooling) & 97 & $14 \cdot 6$ & 0.7 & $13 \cdot 9$ & $5 \cdot 7-32 \cdot 2$ & \\
\hline \multicolumn{7}{|l|}{ Marital status } \\
\hline Married & 93 & $14 \cdot 1$ & 0.6 & 13.4 & $2 \cdot 1-31 \cdot 1$ & \multirow{3}{*}{0.90} \\
\hline Separated, divorced or widowed & 20 & 13.9 & 0.8 & $14 \cdot 4$ & $5 \cdot 7-24 \cdot 8$ & \\
\hline Single & 109 & 14.4 & 0.6 & 13.5 & $2 \cdot 1-32 \cdot 2$ & \\
\hline \multicolumn{7}{|l|}{ Parity (no. of pregnancies) } \\
\hline 0 & 71 & $14 \cdot 7$ & 0.6 & 13.5 & $5 \cdot 5-32 \cdot 2$ & \multirow[t]{3}{*}{0.64} \\
\hline Between 1 and 2 & 78 & 13.8 & 0.8 & $13 \cdot 2$ & $2 \cdot 1-29 \cdot 8$ & \\
\hline 3 or more & 69 & $14 \cdot 11$ & 0.62 & 13.9 & $2 \cdot 1-31 \cdot 1$ & \\
\hline \multicolumn{7}{|l|}{ Smoking status } \\
\hline Non-smoker & 144 & $14 \cdot 1$ & 0.5 & 13.4 & $2 \cdot 1-31 \cdot 1$ & \multirow[t]{2}{*}{0.68} \\
\hline Smoker & 78 & $14 \cdot 4$ & 0.7 & 13.9 & $2 \cdot 1-32 \cdot 2$ & \\
\hline \multicolumn{7}{|l|}{ Physical activity (during leisure time) } \\
\hline No & 196 & $14 \cdot 2$ & 0.4 & 13.4 & $2 \cdot 1-32 \cdot 2$ & \multirow[t]{2}{*}{0.70} \\
\hline Yes & 26 & $14 \cdot 4$ & 0.5 & $14 \cdot 7$ & $4 \cdot 7-27 \cdot 4$ & \\
\hline \multicolumn{7}{|l|}{ Nutritional status } \\
\hline Underweight or normal & 70 & $14 \cdot 0$ & 0.8 & 13.7 & $2 \cdot 1-29 \cdot 8$ & \multirow[t]{2}{*}{0.73} \\
\hline Overweight or obese & 152 & $14 \cdot 3$ & 0.5 & 13.4 & $2 \cdot 1-32 \cdot 2$ & \\
\hline \multicolumn{7}{|l|}{ Folic acid supplementation } \\
\hline No & 218 & $14 \cdot 1$ & 0.4 & 13.5 & $2 \cdot 1-32 \cdot 2$ & \multirow[t]{2}{*}{0.03} \\
\hline Yes & 4 & $24 \cdot 0$ & $5 \cdot 2$ & $29 \cdot 1$ & $15 \cdot 7-29 \cdot 5$ & \\
\hline
\end{tabular}

2009. The results show that folate levels were mostly adequate in women included in the current study. This information, together with current data on NTD prevalence in Chile, suggests that the current folic acid fortification policy is effective and equitable.

The mean serum folate concentration in Chilean women of reproductive age from the MR of Chile was $14.2 \mathrm{ng} / \mathrm{ml}$, lower than the $16.3 \mathrm{ng} / \mathrm{ml}$ determined in Chilean women in $2003^{(14)}$. Serum folate levels were adequate in $89.1 \%$ of women, and no disparities were detected according to socio-demographic variables previously shown to affect folate status, such as educational level, smoking status or $\mathrm{BMI}^{(36)}$. As expected, folic acid supplement intake was associated with higher serum folate levels, but only $1.2 \%$ of the population took supplements. Despite this low level of supplement use, $7 \%$ of women (including supplement users and non-users) exhibited supraphysiological serum folate levels.

Folate concentrations detected by the ENS 2016-2017 were lower to those in the ENS 2009-2010: the mean shifted from 21.2 to $14.2 \mathrm{ng} / \mathrm{ml}$, and the p95 from 38.6 to $24.1 \mathrm{ng} /$ $\mathrm{ml}$. However, a direct comparison between serum folate levels from both surveys is inadequate because different laboratory techniques were used and different subpopulations were included in the ENS 2009-2010 and ENS 2016-2017. The former used direct competitive chemiluminescence immunoassays and included elderly participants, and the latter used competitive electrochemiluminescencebased immunoassay and analysed women of reproductive age, respectively. Indeed, existing evidence shows that higher levels of serum folate are usually detected in participants older than 60 years due to higher intake and/or lower catabolism of folic acid ${ }^{(37)}$. This difference may explain the lower level in serum folate in 2016-2017 v. 2009-2010 surveys. Future evaluation of folate status in Chileans will require the analysis of the target population (young women) in parallel to other populations potentially affected by the fortification policy, for example, children and elderly.

The WHO recommends the microbiological assay as the most reliable method to obtain comparable estimates 
Table 5 Adjusted linear regression model for associations between serum folate levels with socio-demographic variables and nutritional status in women of childbearing age living in urban areas of the Metropolitan Region of Chile

\begin{tabular}{|c|c|c|c|c|}
\hline \multirow[b]{2}{*}{ Variable } & \multirow[b]{2}{*}{$\beta$} & \multicolumn{2}{|c|}{$95 \% \mathrm{Cl}$} & \multirow[b]{2}{*}{$P$} \\
\hline & & Lower limit & Upper limit & \\
\hline $\begin{array}{l}\text { Age (years) } \\
\text { Educational level }\end{array}$ & 0.053 & -0.040 & 0.147 & $\begin{array}{l}0.264 \\
0.939\end{array}$ \\
\hline Low & 0.050 & $-3 \cdot 366$ & 4.465 & 0.782 \\
\hline Medium & $-0 \cdot 104$ & $-1 \cdot 851$ & 1.644 & 0.907 \\
\hline High & 0.000 & & & \\
\hline Marital status & & & & 0.897 \\
\hline Married & 0.055 & $-2 \cdot 075$ & $2 \cdot 186$ & 0.959 \\
\hline Separated, divorced or widowed & -0.491 & $-3 \cdot 274$ & $2 \cdot 291$ & $0 \cdot 728$ \\
\hline Single & 0.000 & & & \\
\hline Parity (no. of pregnancies) & & & & 0.488 \\
\hline 0 & 0.790 & $-2 \cdot 109$ & 3.689 & 0.592 \\
\hline $\begin{array}{l}\text { Between } 1 \text { and } 2 \\
3 \text { or more }\end{array}$ & $\begin{array}{r}-0.814 \\
0.000\end{array}$ & $-2 \cdot 678$ & 1.050 & 0.390 \\
\hline Nutritional status & & & & 0.359 \\
\hline $\mathrm{BMI}\left(\mathrm{kg} / \mathrm{m}^{2}\right)$ & -0.067 & -0.211 & 0.077 & 0.359 \\
\hline Physical activity (during leisure time) & & & & 0.755 \\
\hline $\begin{array}{l}\text { Yes } \\
\text { No }\end{array}$ & $\begin{array}{r}-0.221 \\
0.000\end{array}$ & $-1 \cdot 748$ & $1 \cdot 306$ & 0.775 \\
\hline Smoking status & & & & 0.564 \\
\hline $\begin{array}{l}\text { No } \\
\text { Yes }\end{array}$ & -0.495 & $-2 \cdot 187$ & $1 \cdot 196$ & 0.564 \\
\hline $\begin{array}{l}\text { Yes } \\
\text { Folic acid supplementation }\end{array}$ & 0.000 & & & 0.021 \\
\hline No & -10.893 & -20127 & -1660 & 0.021 \\
\hline Yes & 0.000 & & & \\
\hline
\end{tabular}

of population folate status across different countries ${ }^{(38)}$. However, this method requires standardisation and adjustment of threshold levels to obtain reproducible and comparable results within and among laboratories ${ }^{(38)}$. In our country, the microbiological assay method was not available when the ENS 2016-2017 was undertaken, so we used electrochemiluminescence immunoassay, a commercial protein-based immunoassay used in clinical and research settings, to determine serum folate levels.

The current study shows that serum folate levels are mostly within the normal range in young women living in urban areas of the MR of Chile and suggests that the current folic acid fortification policy is adequate to keep NTD within folate-preventable ranges. In a recent publication, the mean reported NTD prevalence in Chile between 2001 and 2013 was 5.5:10 $000^{(13)}$. The prevalence of NTD in 2018 was 6.4: 10000 live births (C Mellado and RA Pardo, unpublished results). These proportions are in the range of 4-9:10 000 live births expected in countries that have reached adequate folate status ${ }^{(38,39)}$.

Our study has several limitations. Firstly, we were unable to determine folate insufficiency on the basis of an increased risk of NTD because of a mismatch between the assay used to establish this folate insufficiency cut-off (microbiological assay) and the assay we used to determine folate levels in our study (electrochemiluminescence immunoassay) ${ }^{(38)}$. Secondly, the current study only measured the folate levels in women of childbearing age living in the urban MR of Chile because folate integrity could not be ensured for samples transported to the clinical laboratory from other regions. Hence, our study is only representative of women residing in the MR, not in Chile as a whole. Nevertheless, it is important to note that approximately $40 \%$ of Chileans live in the MR. Thirdly, we measured serum folate instead of erythrocyte folate, the latter being a better indicator of long-term folate levels ${ }^{(36)}$. Finally, folate intake was not assessed in the ENS by means of dietary questionnaires (e.g., 24-h recall, food diary or FFQ). This would have enabled us to verify if women of childbearing age are meeting folate intake recommendations. Furthermore, the correlation between serum biomarker levels and women's reported intake might have served as an indirect measure of flour manufacturers' compliance with regulations regarding folic acid fortification in Chile.

Our analysis highlights the importance of performing additional research in order to monitor folate status in different age and sex population subgroups at a national, using the gold standard methods for measuring long-term folate status (microbiological assay in erythrocytes), before considering any further adjustments to the national policy. Technical calculations of the burden of disease due to deficit $v$. excess of folate may also be required to assess the benefit $v$. risk of folic acid fortification in our country objectively. Also, it is fundamental to ensure strict surveillance of the flour and food industries to prevent excessive fortification and addition with folic acid. 
Altogether, the results and discussion described above support maintaining the current fortification policy with folic acid as a measure to maintain folate-preventable ranges of NTD in Chile. The low awareness/adherence and socio-economic disparities in the use of vitamin supplements $^{(8,9,39,40)}$ and the high proportion of unplanned pregnancies in our region ${ }^{(4)}$ further support this view.

\section{Acknowledgements}

Acknowledgements: The authors are grateful to the Ministry of Health from Chile for the free access to their database. All the results obtained from the current study are the responsibility of the author and in no way compromise that institution. The authors thank Luis Villarroel (Department of Public Health, School of Medicine, Pontificia Universidad Católica de Chile) for his support in analyses involving the use of SAS software. Financial support: ENS 2016-2017 was financed by the Ministry of Health from Chile (Ministerio de Salud, Subsecretaría de Salud Pública). Conflict of interest: There are no conflicts of interest. Authorship: D.B., G.E., F.M., M.F. and P.M formulated the research question, designed the study and approved the last version of this manuscript. P.M. was the Director of the ENS 2016-2017, G.E., A.P. and D.B. analysed the data and D.B., G.E., A.P. and P.M wrote the article. Ethics of human subject participation: The current study was conducted according to the guidelines laid down in the Declaration of Helsinki. All procedures involving research study participants were approved by the Ethics Committee from the Pontificia Universidad Católica de Chile and the Chilean Ministry of Health. Written informed consent was obtained from all patients.

\section{References}

1. MRC Vitamin Study Research Group (1991) Prevention of neural tube defects: results of the medical research council vitamin study. Lancet 338, 131-137.

2. Gilbert SF (2006) Developmental Biology, 8th ed. Sunderland, MA: Sinauer Associates.

3. Crider KS, Bailey LB \& Berry RJ (2011) Folic acid food fortification - its history, effect, concerns, and future directions. Nutrients 3, 370-384.

4. Bearak J, Popinchalk A, Alkema L et al. (2018) Global, regional, and subregional trends in unintended pregnancy and its outcomes from 1990 to 2014: estimates from a Bayesian hierarchical model. Lancet Global Health 6, e380-e389.

5. Cuskelly GJ, McNulty H \& Scott JM (1996) Effect of increasing dietary folate on red-cell folate: implications for prevention of neural tube defects. Lancet 347, 657-659.

6. Medawar G, Wehbe T \& Jaoude EA (2019) Awareness and use of folic acid among women of childbearing age. Ann Global Health 85, 54.

7. Williams JL, Abelman SM, Fassett EM et al. (2006) Health care provider knowledge and practices regarding folic acid, United States, 2002-2003. Matern Child Health J 10, S67-S72.
8. Liu M, Chen J, Liu J et al. (2017) Socioeconomic inequality in periconceptional folic acid supplementation in China: a census of 0.9 million women in their first trimester of pregnancy. BMC Pregnancy Childbirth 17, 422.

9. Kinnunen TI, Sletner L, Sommer C et al. (2017) Ethnic differences in folic acid supplement use in a populationbased cohort of pregnant women in Norway. BMC Pregnancy Childbirth 17, 143.

10. Blencowe H, Cousens S, Modell B et al. (2010) Folic acid to reduce neonatal mortality from neural tube disorders. Int J Epidemiol 39(1), i110-i121.

11. Hoddinott J (2018) The investment case for folic acid fortification in developing countries. Ann NY Acad Sci 1414, 72-81.

12. Arth A, Kancherla V, Pachon H et al. (2016) A 2015 global update on folic acid-preventable spina bifida and anencephaly. Birth Defects Res Part A Clin Mol Teratol 106, 520-529.

13. Castillo-Lancellotti C, Tur JA \& Uauy R (2013) Impact of folic acid fortification of flour on neural tube defects: a systematic review. Public Health Nutr 16, 901-911.

14. Hertrampf E, Cortes F, Erickson JD et al. (2003) Consumption of folic acid-fortified bread improves folate status in women of reproductive age in Chile. J Nutr 133, 3166-3169.

15. Lopez-Camelo JS, Orioli IM, da Graca Dutra M et al. (2005) Reduction of birth prevalence rates of neural tube defects after folic acid fortification in Chile. Am J Med Genet Part A 135, 120-125.

16. Llanos A, Hertrampf E, Cortes F et al. (2007) Cost-effectiveness of a folic acid fortification program in Chile. Health Policy $\mathbf{8 3}$, 295-303.

17. Smith AD, Kim YI \& Refsum H (2008) Is folic acid good for everyone? Am J Clin Nutr 87, 517-533.

18. Smith AD, Refsum H, Selhub J et al. (2016) Decision on folic acid fortification in Europe must consider both risks and benefits. BMJ 352, i734.

19. Hirsch S, de la Maza P, Barrera G et al. (2002) The Chilean flour folic acid fortification program reduces serum homocysteine levels and masks vitamin B-12 deficiency in elderly people. J Nutr 132, 289-291.

20. Hirsch S, Sanchez H, Albala C et al. (2009) Colon cancer in Chile before and after the start of the flour fortification program with folic acid. Eur J Gastroenterol Hepatol 21, 436-439.

21. Castillo-Lancellotti C, Margozzini P, Valdivia G et al. (2015) Serum folate, vitamin B12 and cognitive impairment in Chilean older adults. Public Health Nutr 18, 2600-2608.

22. Morris MS, Jacques PF, Rosenberg IH et al. (2007) Folate and vitamin B-12 status in relation to anemia, macrocytosis, and cognitive impairment in older Americans in the age of folic acid fortification. Am J Clin Nutr 85, 193-200.

23. Patel KR \& Sobczynska-Malefora A (2017) The adverse effects of an excessive folic acid intake. Eur J Clin Nutr 71, 159-163.

24. Sanchez H, Hossain MB, Lera L et al. (2017) High levels of circulating folate concentrations are associated with DNA methylation of tumor suppressor and repair genes p16, MLH1, and MGMT in elderly Chileans. Clin Epigenet 9, 74 .

25. Wiegand H (1968) Kish, L.: Survey Sampling. John Wiley \& Sons, Inc., New York, London 1965, IX + 643 S., 31 Abb., 56 Tab., Preis 83 s. Biometr $Z$ 10, 88-89.

26. Mindell JS, Giampaoli S, Goesswald A et al. (2015) Sample selection, recruitment and participation rates in health examination surveys in Europe: experience from seven national surveys. BMC Med Res Methodol 15, 78 .

27. WHO Collaborating Centre for Drug Statistics Methodology (2018) Guidelines for ATC classification and DDD assignment. Oslo, Norway. 
28. Mindell JS, Moody A, Vecino-Ortiz AI et al. (2017) Comparison of health examination survey methods in Brazil, Chile, Colombia, Mexico, England, Scotland, and the United States. Am J Epidemiol 186, 648-658.

29. Mujica-Coopman MF, Navarro-Rosenblatt D, López-Arana S et al. (2020) Nutrition status in adult Chilean population: economic, ethnic and sex inequalities in a post-transitional country. Public Health Nutr 5, 1-12.

30. Bailey LB, Stover PJ , McNulty H et al. (2015) Biomarkers of nutrition for development-folate review. J Nutr $\mathbf{1 4 5}$, 1636s-1680s.

31. World Health Organization (2015) Serum and red blood cell folate concentrations for assessing folate status in populations. In Vitamin and Mineral Nutrition Information System. Geneva, Switzerland: WHO. http://apps.who.int/iris/bitstream/10665/ 162114/1/WHO_NMH_NHD_EPG_15.01.pdf?ua=1 (accessed august 2020).

32. Pfeiffer CM, Caudill SP, Gunter EW et al. (2005) Biochemical indicators of $\mathrm{B}$ vitamin status in the US population after folic acid fortification: results from the National Health and Nutrition Examination Survey 1999-2000. Am J Clin Nutr 82, 442-450.

33. World Health Organization (1995) WHO Expert Committee on Physical Status: The Use and Interpretation of Anthropometry. Geneva, Switzerland: World Health Organization.
34. de Onis M, Onyango AW, Borghi E et al. (2007) Development of a WHO growth reference for school-aged children and adolescents. Bull World Health Organ 85, 660-667.

35. Ren Y, Zhang B \& Qiao H (1999) A simple Taylor-series expansion method for a class of second kind integral equations. J Comput Appl Math 110, 15-24.

36. Piyathilake C, Eom SY, Hyun T et al. (2013) Determinants of neural tube defect (NTD)-protective circulating concentrations of folate in women of child-bearing age in the US post-folic acid fortification era. Nutr Res Pract 7, 315-325.

37. Pfeiffer CM, Sternberg MR, Fazili Z et al. (2015) Folate status and concentrations of serum folate forms in the US population: National Health and Nutrition Examination Survey 2011-2012. Br J Nutr 113, 1965-1977.

38. Cordero AM, Crider KS, Rogers LM et al. (2015) Optimal serum and red blood cell folate concentrations in women of reproductive age for prevention of neural tube defects: World Health Organization guidelines. Morbid Mortal Wkly Rep 64, 421-423.

39. Ray JG, Singh G \& Burrows RF (2004) Evidence for suboptimal use of periconceptional folic acid supplements globally. BJOG: Int J Obstetr Gynaecol 111, 399-408.

40. Pardo VR, Lay-Son RG, Aranda Ch W et al. (2007) Awareness and knowledge of the use of folic acid in the prevention of neural tube defects: a survey of women living in Santiago, Chile. Rev Med Chile 135, 1551-1557. 